\title{
Research Ability Training of Oil Gas Storage and Transportation Engineering Students in New Local Universities
}

\author{
Hui Huang, Xianghong Jin, and Jianghua Fang \\ School of Chemical Engineering, Ningbo University of Technology, Ningbo, Zhejiang, China (huihuang@nbut.edu.cn)
}

\begin{abstract}
New local universities are important part of higher education in China, research ability training of students major in oil gas storage and transportation engineering not only is one of hot subjects of current higher education reform and development in China, but also is the objective requirement of local and industrial economic development under new circumstances. Ningbo University of Technology was tanken as an example to set the research ability training goal for students from oil gas storage and transportation engineering major in school of chemical engineering. Cultivation routes of developing scientific research intersest and sense, building double monitorail system by combining tutorial system and montitorial system, project-based managing and teamship operating were introduced. Assuring measures including institutional guarantee, incentive and awarding policy, preferential measures of teaching and research section were established afterward.
\end{abstract}

Keywords—research ability, teamship, project-based, double monitorail

\section{新建地方本科院校油气储运工程专业学生科研能力培 养初探}

\author{
黄辉 金向红 房江华 \\ 宁波工程学院化工学院，宁波，浙江，中国
}

摘 要 新建地方本科院校是我国高等教育的重要组成部分, 培养油气储运工程专业学生的科研能力既是当前高等教育改革与发 展的主题之一, 也是新形势下地方和行业经济发展的客观要求。本文以宁波工程学院为例, 结合化工学院油气储运工程专业实际, 确 定了油气储运工程专业学生科研能力培养的目标, 探索了培养科研兴趣和意识、建立导师制和导生制相结合的双导制、项目制管理和 团队化运作等培养途径，建立了包括制度保障、激励和奖励政策、教研室优惠措施等在内的保障机制。

关键词 科研能力，团队化，项目制，双导制

1. 引言

新建地方本科院校主要是指 20 世纪 90 年代以来, 随 着我国高等教育规模的扩张和体制改革的不断深化, 由多 所不同层次、不同类型学校合并或专科学校独立升格的新 型本科院校。据统计, 截止到 2013 年 3 月, 新建地方本科 院的数量已占到了全国本科院校数量的近 $41 \%$, 已成为我 国高等教育的重要组成部分。当前, 我国正处在改革发展

宁波市教育科学规划研究课题支持 (项目编号: YGH032)
的关键阶段, 以科技创新推动转方式调结构战略的实施凸 显出创新人才培养的重要性。高等院校作为培养创新人才 的重要基地, 正在掀起新一轮的高等教育改革浪潮。《高 等教育法》规定: “本科教育应当使学生比较系统地掌握本 学科和专业必须的理论基础知识, 掌握本专业必要的基本 技能、方法和相关知识, 具有从事本专业实际工作和研究 工作的初步能力。”; 教育部 2012 年印发的《关于全面提高 高等教育质量的若干意见》更是明确提出支持本科生参与 
科研活动, 早进课题、早进实验室、早进团队。因此, 培 养本科生的科研能力, 是高等教育的基本任务, 更是提高 本科生的创新能力, 实现创新人才培养的有效途径和方法 之一。而相较于 “ 985 ”、“211”、省属重点高校, 新建地方 本科院校在人才培养理念、师资队伍水平、教学科研资源 和生源质量等软、硬件方面都存在着非常明显的差距, 如 何走出自己特色的本科生科研能力培养之路是新建地方本 科院校亟待解决的问题。

宁波工程学院的前身为宁波高等专科学校, 是 2004 年 经教育部批准升格更名而来的新建地方本科院校。基于宁 波市打造国家化港口城市和临港石油化工产业快速发展的 需要, 并以港口油气储运和石化企业液体化学品储运与安 全管理的人才需求为出发点, 宁波工程学院化工学院于 2005 年开始招收油气储运工程专业本科生, 目前已发展到 近 300 名在校生的规模。我国的油气储运工程本科教育已 经历了六十多年的发展, 在各方面都取得了很大的成就。 近几年, 新方法、新工艺、新技术层出不穷, 石油天然气 工业和石油化工工业都发生了较大变化, 培养油气储运工 程专业的创新人才也是新形势下地方和行业经济发展的客 观要求。本文以宁波工程学院为例, 立足油气储运工程专 业的实际, 对学生科研能力的培养进行了初步探索, 为新 建地方本科院校学生的科研能力培养提供借鉴和参考。

\section{2. 油气储运工程专业学生科研能力培养目标和途径}

\section{1 培养目标}

本科生获取的初步科研能力主要是为今后走上工作岗 位和从事专业科学研究打基础, 并不是在大学期间就期望 成为高水平的专业性研究人员。所以从本质上讲, 本科生 的科研实际上是一种基于专业知识学习的探究性活动。研 究不是唯一的目的, 也是培养学生创新能力的手段, 使其 具备科研素质, 包括树立科研意识, 激发科研兴趣, 初步 掌握科研方法, 培养科研精神等。因此, 根据本科生科研 的实质, 结合宁波工程学院 “知行合一” 的培养理念和油 气储运工程专业的特点, 确定了培养油气储运工程专业学 生科研能力的培养目标, 即通过让学生参加各种形式的科 研活动, 培养出适应地方经济和社会需要的、基础知识扎 实、专业核心技能强、综合素质高的应用开发型高级技术 人才; 培养学生树立潜心捕捉问题的探求欲, 初步掌握如 何调研和制定研究方案、开展实验研究、进行数据分析统 计、撰写研究报告或论文等方面的基本手段和具体方法, 具备敢于探索、不惧失败、实事求是、团队合作和作风严 谨等优秀科研素质。

\section{2 培养途径}

本科生科研能力的培养途径多种多样, 在选择和制定 油气储运工程专业学生的科研能力培养途径时, 既要基于 宁波工程学院为新建地方本科院校这一校情及现有的政策 和措施, 也要结合油气储运工程专业的特点和实际。现主 要从以下几个方面培养油气储运工程专业学生的科研能 力。

培养科研兴趣和意识。兴趣是最好的老师, 在新生处 于专业学习积极性高的阶段时, 通过始业教育中老师对学 生科研现状的描述、在研项目的介绍, 让新生对专业产生 认同感, 了解专业前言研究, 在拓宽学术视野的同时, 激 发学生的求知欲和科研兴趣, 初步具备科研意识。同时, 油储学生党支部组织在科研方面取得优异成绩的高年级学 生, 面向新生开展交流和参观校大学生人才培养创新成果 展厅、专业实验室等活动, 介绍自己的宝贵经验和个人收 获, 通过亲身经历和现身说法, 帮助新生对大学期间参与 科研活动有更清晰的了解, 也为新生树立精神榜样。

建立导师制和导生制相结合的双导制。本科生导师制 是近年来我国高等教育体制改革过程中探索出的一项新的 学生教育管理工作机制, 其源于精英高等教育时期的英国, 是英国的导师制与美国的学分制结合的产物。化工学院的 导师制最早可追溯到 2008 年, 一开始是学生组织的自发行 为, 个别学生主动找教师指导其调研型课题的开展式; 后 来发展到学院建立集中选拔科研助手制度, 将教师的科研 信息和需求向学生发布, 再将学生报名表发给教师挑选, 有效地将学生、教师和科研结合在一起, 通过学生在教师 指导下开展科学研究, 培养学生的科研能力; 2012 年宁波 工程学院开始试行 “合协号” 本科生导师制, 师生双向选 择, 以结对的形式加入该计划, 由教师对结对学生进行思 想、学习、生活等方面的教育和引导, 实现学生个性的全 面发展目标, 培养出优秀和特色人才。油气储运工程专业 属于新建地方本科院校的新专业, 生师比较高, 且符合一 定条件又愿意指导学生科研的导师数量更少, 因此我们在 积极参与实施院、校两级的导师制的基础上, 建立了导师 制和导生制相结合的双导制, 即指导教师与若干个专业素 质高、综合能力强的学生实行导师制, 指导教师的有限精 力可以集中、有效地将学生培养成为学生科研骨干, 然后 学生科研骨干与其他同级或低年级学生实行导生制, 由学 生科研骨干协助指导教师指导普通学生的科研活动。双导 制在一定程度上有效地解决了目前油气储运工程专业学生 科研能力培养中导师制所面临的受益学生面有限、规模化 
效益差的问题, 使得参与的学生都能够不同程度地在科研 能力上得到锻炼和提高。

项目制管理和团队化运作。项目制管理就是将课题研 究项目化, 围绕项目进行有效地费用、进度和质量控制, 实现项目目标并达到项目各参与方满意的过程; 团队化运 作就是充分利用团队优势, 整个团队中各个成员的资源和 特长, 使团队产出最大化。学生参与的科研课题本身具有 典型的一次性、独特性和阶段性等项目特征，同时围绕科 研课题所组成的研究团队也是一个临时性的组织, 它并不 以课题的启动和完成作为成员进入和推出的标志，而是以 本科生入校、毕业时间和课余时间的可支配程度作为团队 调整的依据。因此, 可以通过项目制管理和团队化运作来 培养学生的科研能力, 这不仅可以提高科研课题的研究质 量、学生的参与度和满意度, 还可以降低学生的流动性引 起的团队磨合损失。在油气储运工程专业学生科研能力培 养的实际操作中, 我们以学生科研骨干为项目负责人, 在 导师的指导下, 带领导生制中所协助指导的其他学生, 独 立开展课题的调研和立项、方案制定和实施、论文撰写和 发表以及最后的项目结题等工作, 并根据每个组员的特点, 发挥并建立不同成员的优势，使每个学生都受到项目不同 阶段所带来的不同锻炼, 同时也让低年级学生在此过程中 逐渐成长为学生科研骨干，实现课题研究的连贯性。

\section{3. 油气储运工程专业学生科研能力培养的保障机制}

培养油气储运工程专业学生科研能力时, 必须要有良 好的实施环境, 在制度、政策和措施等方面提供有力保障, 不断完善培养机制。

\section{1 制度保障}

自 2009 年以来, 宁波工程学院先后出台了《宁波工程 学院优秀学生培养管理办法》、《宁波工程学院大学生科研 项目管理办法》、《宁波工程学院科技创新活动管理办法》、 《关于深化教学改革提高教学质量的若干意见》和《宁波 工程学院 “合协号” 本科生导师制管理办法》等系列文件, 不断营造校园学术科技氛围、激发学生参与创新活动的热 情、提升学生创新能力, 这些基于学校层面的顶层设计, 为油气储运工程专业学生科研能力培养奠定了政策基础和 制度保障。

\section{2 激励和奖励政策}

适当的激励和奖励政策的实施, 有助于完善学生科研 能力的评价体系, 对于参与科研活动的学生来说也具有巨
大的精神动力和激励作用, 能促使学生一心一意地投入到 科研工作中去, 使自己的努力成果得到认可; 同时, 也对 其他学生具有一定的导向作用, 促进良好学习、学术风气 的形成。《宁波工程学院关于学生参加科技、文体类竞赛奖 励办法》明确规定学生科研成果不仅可以根据论文、专利 的级别和排名获得不同等级的奖励, 还能认定为特色学分 抵各专业培养计划中公选课和专业选修课的学分, 对于特 别突出的与专业相关的高水平第一作者成果, 甚至可以申 请替代学生毕业论文 (设计)。《宁波工程学院王伟明新苗 奖和育才奖评选办法》、《宁波工程学院王伟明助创资金管 理办法》则充分利用社会资助办学资金, 提高学生科研项 目的立项资助率, 奖励在创新活动中表现突出的学生和指 导教师。化工学院更是在上述政策的基础上, 结合学院实 际, 制定了《化工学院学生论文奖励办法》, 以期鼓励更多 的学生参与教师的科创活动, 更多的老师参与指导学生, 并出更多高水平的研究论文和专利。

\section{3 教研室优惠措施}

油气储运教研室根据油气储运工程专业实际, 将学生 科研工作与教学培养计划相结合, 把学生科研能力培养环 节与部分教学实践环节融合在一起。比如允许并鼓励学生 在导师的指导下将大一的社会实践、大二大三的两次学年 论文以及大四最后的毕业论文 (设计) 与自己的科研工作 结合起来, 把所学的基础知识和专业知识综合应用到学科 前言领域实际科学问题的实践探索中去, 在完成科研项目 的过程中, 同时陆续完成了教学培养计划规定的任务。改 革学生奖学金评选及管理方法, 针对毕业生专门设立毕业 生奖学金, 包括根据考取高校级别分类的考研奖和根据完 成质量分类的毕业论文 (设计) 奖。优先选派热衷于指导 学生开展科研工作的专业教师出国访学或进修深造, 增加 优秀指导教师的数量、提升学生科研活动指导能力, 不断 提高双导制在学生科研能力培养中的作用。

\section{4. 结束语}

本科生科研能力的培养是一个系统工程, 它是由包括 各种要素、各类环境共同作用的一系列过程或活动所构成 的统一整体, 只有系统内的各个因素相互配合、相互作用, 才能形成良性循环, 逐渐提高学生的科研能力。新建地方 本科院校在局限较多的情况下, 如何有效地整合现有资源, 通过培养学生的科研能力来提高学生的创新能力, 并最终 实现创新人才的培养, 显得尤为重要。将来, 会在油气储 运工程专业的课程结构、课堂教学形式、实验教学体系、 实践平台建设等方面继续探索与实践, 构建新建地方本科 院校油气储运工程专业学生科研能力培养的长效体系。 


\section{参考文献(References)}

[1] H. Zhao, "Research on project-based innovation ability traning of undergraduates," Education and Vocation, no. 26, pp. 184-185, 2012.

[2] J. Liang, "Teaching reform of oil gas storage and transportation engineering under new circumstances," Petroleum Education, no. 3, pp. 20-23, 2013.

[3] W. Li, B. Peng, and X. Yuan, "Research on strategy of traning and promoting college students in new universities," Education Teaching Forum, no. 40, pp. 117-119, 2013.
[4] S. Huang, R. Li, Q. Pan, and S. Huang, "Study and practice of training scientific research ability of college students in undergraduate tutorial system," Higher Education Forum, no. 2, pp. 22-24, 2011.

[5] J. H. Wang, J. Zhou, A. C. Yue, Z. H. Yang, and X. G. Zhang, On the construction and practice of "123 mode of "PETOE", Research in Higher Education of Engineering, no. 3, pp. 47-52, 2012.

[6] H. Huang and X. H. Jin, Reflections on teaching reform on pump and compressor coures, Journal of Ningbo University of Technology, vol. 24, no. 3, pp. 78-80, 2012. 